\title{
Flammability properties of thermally dried sewage sludge
}

\author{
Nieves Fernandez-Anez ${ }^{\text {a,* }}$, Javier Garcia-Torrent ${ }^{\text {a,b }}$, Ljiljana Medic-Pejic ${ }^{a}$ \\ ${ }^{a}$ Department of Chemical Engineering and Fuels (UPM Technical University of Madrid, Spain), C/Alenza 4, 28003 Madrid, Spain \\ ${ }^{\mathrm{b}}$ Laboratorio Oficial Madariaga, LOM (UPM Technical University of Madrid, Spain), C/Eric Kandel, 1 - (TECNOGETAFE), Parque Cientifico y Tecnológico de la UPM, Getafe, \\ 28906 Madrid, Spain
}

\section{H I G H L I G H T S}

- Flammability parameters of sludge are presented.

- Relationships between chemical and flammability properties of sludge are analyzed.

- Physical and chemical properties of sludge dusts affects their explosibility.

- Seasons and origins of sludge should lead to a differentiation among samples.

\begin{abstract}
A B S T R A C T
The treatment and disposal of sewage sludge is becoming an urgent need whereby different technologies were developed and integrated into the waste cycle all over the world. One of the most used technologies is the thermal drying of the sludge. Thermally dried sewage sludge has interesting properties that allow its use as an alternative fuel, but also needs some consideration from the point of view of its safe operation.

The aim of this study was the research on the flammability properties of sewage sludge, including ignition sensitivity, explosion severity, thermal sensitivity and thermal stability. Furthermore relationships among those properties and composition parameters have been determined, added to the study of their variation depending on their origin or season. Finally, properties related to spontaneous combustion were determined. To study these relationships and characteristics sludge samples were selected from different locations in Spain and taken during different seasons.
\end{abstract}

\section{Introduction}

Due to the arise of consumption and the need to preserve water as an essential resource of life, there has been an increase of the existing wastewater treatment plants (WWTP) in order to collect the wastewater from a population or industry and, after a series of treatments and processes, return it to a receiving stream [1,2].

Actually, many actions are being carried out focused on the reuse of the waste produced by these WWTP [3]. One of the most developed reusing methods is thermal drying. This is an attractive alternative and it also provides the opportunity for an economical resource recovery [4]. Actually, thermal drying of sewage sludge is the most common method used in 2 countries of the 27 forming the EU members, a common method on 12 countries and a rare method in 1 country [5].

\footnotetext{
* Corresponding author. Tel.: +349133641 73; fax: +3491336 6948 .

E-mail address: nieves.fernandez@upm.es (N. Fernandez-Anez).
}

Most occupational hazards in wastewater treatment, including methane production, are well known [6]. Focusing on the thermal drying process, there is a general risk understudied that produces serious consequences: the risk of generation of explosive atmospheres (ATEX) caused by dusts and a possible consequent explosion [7]. This risk is present in all the industrial plants, and may be well studied to avoid accidents [8].

Dust generated in the thermal drying of sewage sludge is a fuel product [9] and it can produce an explosion due to the chemical reaction: fuel + oxygen $=$ oxides + heat $[10]$.

To design the prevention and protection measurements needed in all the industrial plants a complex methodology is necessary to take into account all the existing hazards [11]. Several researchers have demonstrated that it is essential to characterize the sewage sludge [12,13]. Characterization of new fuels, mainly biomass, has experience an important advance through various researches in recent years [14,15], trying to have a complete scenario of their hazards likes the one nowadays existing for coal [16]. 
First of all, it is necessary to take into account the chemical composition of the sewage sludge. This chemical composition varies among different samples but it is always formed by organic matter, inorganic matter and gases [17] and approximately $75 \%$ of suspended solids and $40 \%$ of filterable solids are organic in nature [18]. As an example of the influence of the chemical composition in the explosibility of dusts, it is shown that the inorganic matter of coal has a negative correlation with the self-heating rate [19].

Other relations that are observed in other substances are those existing among different flammability parameters and the particle size distribution and concentration [20,21], the humidity [22] and the dustiness [23].

All these parameters depend on the sewage sludge studied, and some seasonal and time variability of the composition differences are shown in various studies [24,25].

The aim of this paper is to determine the relations among different explosibility parameters and also among them and the chemical parameters to try to avoid these risks. Also the variability due to seasonal and geographical parameters is studied. Finally, the selfheating of sewage sludge is studied, since this product may be stored for long periods and self-ignition temperature is an important parameter [26].

\section{Materials and methods}

Twenty sewage sludge thermally dried samples have been studied. Those samples have been chosen in order to study seasonal and regional variations, so the samples come from different places and also from different seasons. The samples have been collected in eight WWTP belonging to three regions in Spain: Barcelona, Madrid and Málaga. According to the season when the samples have been collected, they are classified in summer samples or winter samples. If the samples have been collected between May and September, they are classified as summer samples. Otherwise, they have been classified as winter samples. The samples collected are detailed in Table 1.

For all the samples, ultimate and proximate analyses have been conducted and granulometry have been determined. Depending on the results of these tests, ten samples have been selected to develop the ignition sensibility, explosion severity and thermal susceptibility analyses. Finally, due to these results the thermal stability analyses have been done to three samples.

Among all these tests, some are standardized and well known tests, such as ignition sensibility (flammability), explosion severity

Table 1

Collected samples.

\begin{tabular}{lllrrr}
\hline Sample & Origin & Season & $\mathrm{d} 10(\mu \mathrm{m})$ & $\mathrm{d} 50(\mu \mathrm{m})$ & $\mathrm{d} 90(\mu \mathrm{m})$ \\
\hline LRET-101 & Barcelona & Summer & 15.4 & 67.9 & 355.3 \\
LRET-102 & Barcelona & Summer & 111.9 & 339.5 & 815.8 \\
LRET-103 & Barcelona & Winter & 23.4 & 100.4 & 289.2 \\
LRET-104 & Madrid & Summer & 96.7 & 382.2 & 818.6 \\
LRET-105 & Madrid & Summer & 88.6 & 397.2 & 844.1 \\
LRET-106 & Madrid & Summer & 13.2 & 77.7 & 371.2 \\
LRET-107 & Madrid & Winter & 69.2 & 385.9 & 853.9 \\
LRET-108 & Madrid & Winter & 10.9 & 30.2 & 160.5 \\
LRET-110 & Madrid & Winter & 88.2 & 382.5 & 839.7 \\
LRET-111 & Madrid & Winter & 10.3 & 43.0 & 383.9 \\
LRET-112 & Málaga & Winter & 7.5 & 27.3 & 62.2 \\
LRET-113 & Málaga & Winter & 81.3 & 517.6 & 1150.7 \\
LRET-114 & Barcelona & Summer & 69.7 & 298.9 & 664.3 \\
LRET-115 & Barcelona & Summer & 152.3 & 492.5 & 1098.7 \\
LRET-116 & Barcelona & Winter & 52.3 & 531.6 & 1218.2 \\
LRET-117 & Barcelona & Winter & 34.1 & 74.4 & 348.3 \\
LRET-118 & Madrid & Winter & 7.4 & 20.6 & 178.9 \\
LRET-119 & Madrid & Winter & 110.3 & 214.4 & 653.5 \\
LRET-120 & Barcelona & Winter & 3.5 & 19.9 & 75.2 \\
LRET-121 & Madrid & Summer & 32.1 & 286.3 & 919.7 \\
\hline
\end{tabular}

(explosibility) or limiting oxygen concentration. Table 2 shows the European Standards followed to determine them.

Thermal susceptibility analyses are less-known in terms of the lack of standardized procedures. They consist of thermogravimetric analysis (TG), differential scanning calorimetric analysis (DSC), Maciejasz Index (MI), characteristic temperature ( $\left.T_{\text {charact }}\right)$ and volatiles emission temperature (TEV).

Finally thermal stability can be explained in terms of the tendency to self-heating. There are standard methods intended to the classification of goods for transportation, according to the ONU-N4 Division 4.2, or intended to the determination of the self-ignition temperature (TSI), according to EN 15188.

\subsection{Test procedures}

In thermogravimetric analysis (TG) the weight of the sample is measured as a function of its temperature when heated following a programmed heating rate. Fig. 1 shows a typical TG plot, with the derivative curve dTG superimposed, where some significant parameters can be defined, such as the combustion induction temperature (IT) and the maximum weight loss temperature (MLT).

In the case of Differential Scanning Calorimetry (DSC) the sample is heated at a regular rate, previously established and a reference inert product is placed in another crucible. The difference in temperature between the sample and the reference is measured and recorded against the temperature of the oven and the exchanges of heat in the sample are determined. Fig. 2 shows a typical DSC record. The parameters used to characterize different substances are the minimum temperature at which the exothermic reaction begins (initial temperature, IET), the maximum temperature reached during the exothermic reaction (final temperature, FET) and the temperature at which the fast exothermic reaction commences (change of slope temperature, CST).

The characteristic temperature ( $T_{\text {charact }}$ ) [27] is determined by thermogravimetric tests adding an oxygen stream. The oxygen accelerates the oxidation process so that the sample suffers a sudden loss of weight. This loss happens at a different characteristic temperature for each sample, the lower the temperature, the higher thermal susceptibility to oxidation. According to this parameter samples can be classified by its self-ignition risk [28].

Maciejasz Index (MI) measures the required time $(t)$ to produce a temperature increase of $65 \mathrm{~K}$ in the sample, when it is attacked by hydrogen peroxide. The Maciejasz index is calculated as $\mathrm{MI}=100 / t$. It determines the susceptibility to the self-combustion due to the oxidation of some compounds in the substance that show avidity to react with oxygen, for instance pyrites in coals. This method is frequently used for coals, especially when their sulfur content is high.

The ignition temperature of emitted volatile matter (TEV) can be considered as a kind of flash point for solids. When a sample

Table 2

Properties determined and European Standards followed to determine.

\begin{tabular}{ll}
\hline Property & $\begin{array}{l}\text { European } \\
\text { Standard }\end{array}$ \\
\hline Elemental analysis (C, H, N) & EN 15104 \\
Ash content & EN 14775 \\
Volatiles content & EN 15148 \\
Humidity & EN 14774 \\
Minimum ignition temperature (layer: MITl, cloud: & EN 50281-2-1 \\
$\quad$ MITc) & EN 14034-3 \\
Lower explosion limit (LEL) & EN 13821 \\
Minimum ignition energy (MIE) & EN 14034-1 \\
Maximum explosion pressure $\left(P_{\text {max }}\right)$ & EN 14034-2 \\
Dust specific constant $\left(K_{\text {max }}\right)$ & EN 14034-4 \\
Limiting oxygen concentration (LOC) &
\end{tabular}




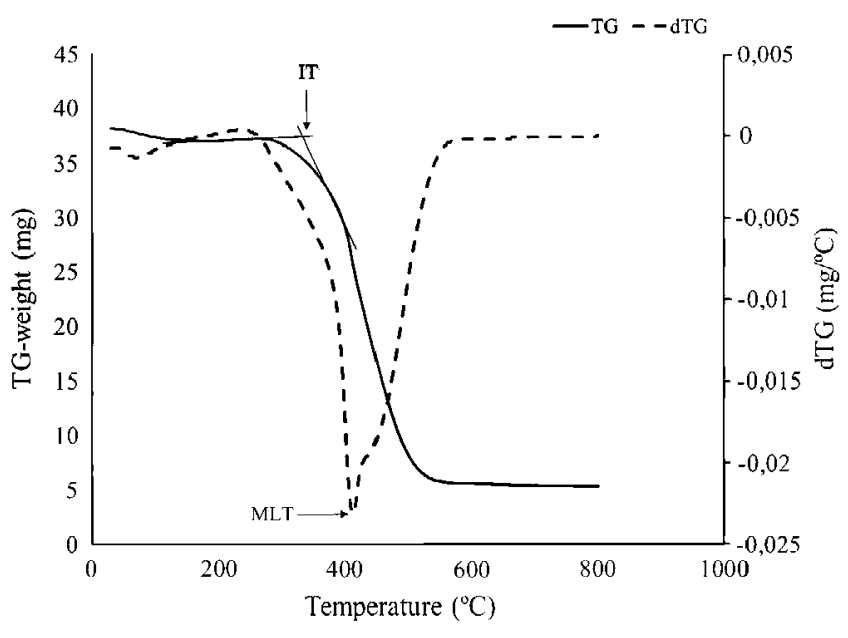

Fig. 1. Thermogravimetric analysis plot.

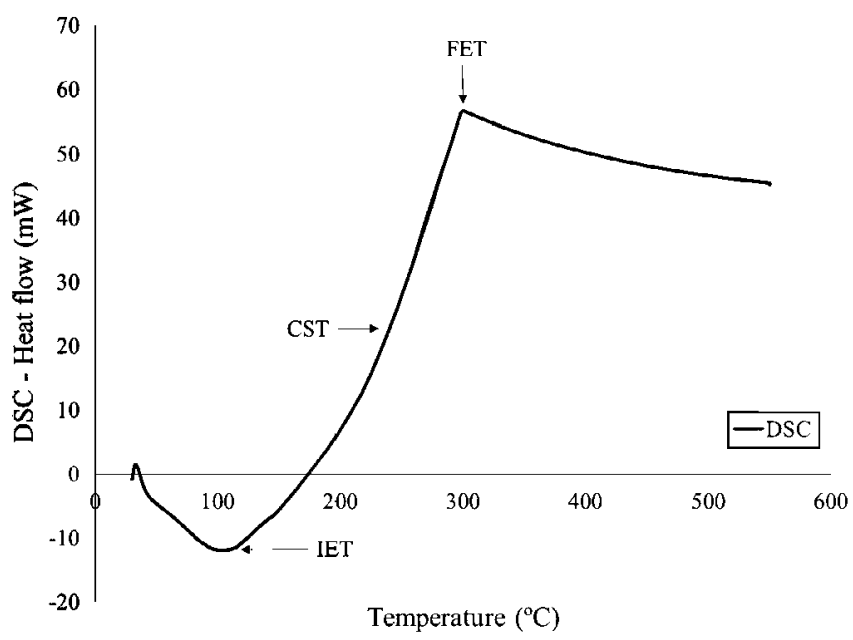

Fig. 2. Differential scanning calorimetry record.

is progressively heated it can decompose and release different gases, some of them being flammable. When an ignition source is applied to the volatile matter released from the sample, the appearance of flames can be observed. It provides an interesting safety issue for organic products that can release flammable combustion products, making the product more hazardous.

Isothermal Oven Tests are useful to detect substances liable to spontaneous combustion. Such substances are classified as Division 4.2 according to the UN recommendations on the transport of dangerous goods. The classification procedure should be undertaken before a product is offered for transport. Tests are performed to determine if substances in a $25 \mathrm{~mm}$ or $100 \mathrm{~mm}$ sample cube, at test temperatures of $100^{\circ} \mathrm{C}, 120^{\circ} \mathrm{C}$ and $140^{\circ} \mathrm{C}$, undergo spontaneous ignition or dangerous self-heating, which is indicated by a $60 \mathrm{~K}$ rise in temperature over the oven temperature within $24 \mathrm{~h}$. These criteria are based on the self-ignition temperature of charcoal, which is $50^{\circ} \mathrm{C}$ for a sample cube of 27 cubic meters.

Self-ignition temperature (TSI) is the temperature at which a given volume of dust will ignite. The experimental basis for describing the self-ignition behavior of a given dust is the determination of the self-ignition temperatures of differently-sized bulk volumes of the dust by isothermal hot storage experiments (storage at constant ambient temperatures) in commercially available drying ovens. The results reflect the dependence of self-ignition temperatures upon dust volume.
The self-ignition temperature may be extrapolated for different volumes, so it represents a generalization of UN tests to any volume. Particularly SIT can be extrapolated to the volumes used in UN tests.

\subsection{Collecting data}

A number of samples have been subjected to those test procedures, measuring many parameters and obtaining a large number of experimental data. Statistical analysis has been applied to these data with a first aim of understanding the behavior of sludge, where correlations between those parameters can provide useful information. The second aim was to determine the similarity between the samples collected based on two parameters: the location where the samples were collected and the season when the samples were collected.

This statistical analysis includes correlation analyses, discriminant analyses and principal component analysis. The study was carried out in two distinct stages: first the chemical composition was studied for a number of samples, selecting some of them for the detailed tests carried out in the second stage. The first stage included all twenty collected samples, whose chemical composition was determined. The second stage corresponded to the selected ten samples whose flammability, explosibility and thermal behavior were analyzed.

\section{Results}

Ultimate and proximate analyses on a dry basis were done to all the twenty samples, as detailed in Table 3. Hydrogen, nitrogen and sulfur content values have a low standard deviation, while variations obtained for carbon, ash content, moisture and volatile matter are higher.

According to the results of the previous analyses, ten samples were selected in order to choose the largest range of values. Ignition sensitivity, explosion severity and thermal stability analyses were determined to those ten samples, and results are shown in Tables 4-6. These results show a wide range of variation in almost all the parameters studied. MITl values have a variation of $150 \mathrm{~K}$, consistent with the observed variation of MITc values, $190 \mathrm{~K}$. The other two parameters included in the ignition sensitivity group

Table 3

Chemical analyses.

\begin{tabular}{|c|c|c|c|c|c|c|c|}
\hline \multirow[t]{2}{*}{ Sample } & \multicolumn{4}{|c|}{ Ultimate analysis (wt\%) } & \multicolumn{3}{|c|}{ Proximate analysis (wt\%) } \\
\hline & C & $\mathrm{H}$ & $\mathrm{N}$ & $S$ & $\operatorname{Ash}^{\mathrm{a}}$ & Moisture & Volatiles $^{a}$ \\
\hline LRET-101 & 37.43 & 4.91 & 3.01 & 0.61 & 32.20 & 6.10 & 62.30 \\
\hline LRET-102 & 28.48 & 3.56 & 2.96 & 0.84 & 48.10 & 2.70 & 52.50 \\
\hline LRET-103 & 33.72 & 4.94 & 5.00 & 1.63 & 43.90 & 11.10 & 59.90 \\
\hline LRET-104 & 34.72 & 4.70 & 4.46 & 1.24 & 44.80 & 4.80 & 54.40 \\
\hline LRET- 105 & 35.76 & 4.74 & 4.52 & 1.31 & 45.00 & 6.50 & 53.50 \\
\hline LRET-106 & 33.83 & 4.52 & 4.75 & 1.61 & 45.00 & 7.80 & 52.90 \\
\hline LRET- 107 & 31.90 & 4.77 & 5.01 & 1.21 & 41.70 & 5.60 & 55.40 \\
\hline LRET-108 & 29.57 & 4.45 & 4.70 & 1.31 & 46.10 & 7.10 & 54.60 \\
\hline LRET- 110 & 31.73 & 4.69 & 4.89 & 1.14 & 41.80 & 4.40 & 57.80 \\
\hline LRET-111 & 30.23 & 4.50 & 4.83 & 1.49 & 44.30 & 6.20 & 54.20 \\
\hline LRET-112 & 36.13 & 5.19 & 4.51 & 4.90 & 37.10 & 5.70 & 62.30 \\
\hline LRET-113 & 34.72 & 4.96 & 5.13 & 2.24 & 38.10 & 3.00 & 60.40 \\
\hline LRET-114 & 35.28 & 4.96 & 4.11 & 2.18 & 40.40 & 3.90 & 57.60 \\
\hline LRET-115 & 32.28 & 4.67 & 4.65 & 1.96 & 40.00 & 14.10 & 56.60 \\
\hline LRET- 116 & 44.81 & 6.69 & 5.36 & 1.30 & 20.20 & 5.80 & 73.90 \\
\hline LRET-117 & 38.30 & 6.33 & 3.72 & 1.08 & 38.50 & 2.40 & 57.40 \\
\hline LRET- 118 & 34.80 & 6.45 & 5.20 & 1.39 & 36.40 & 9.80 & 60.20 \\
\hline LRET-119 & 31.90 & 5.63 & 4.27 & 0.89 & 45.40 & 1.30 & 51.50 \\
\hline LRET-120 & 38.20 & 6.53 & 4.67 & 1.44 & 34.50 & 3.60 & 58.40 \\
\hline LRET-121 & 33.40 & 6.24 & 4.37 & 1.23 & 41.70 & 6.20 & 57.00 \\
\hline
\end{tabular}

${ }^{a}$ Dry basis. 
Table 4

Ignition sensitivity and explosion severity.

\begin{tabular}{|c|c|c|c|c|c|c|c|}
\hline \multirow[t]{2}{*}{ Sample } & \multicolumn{4}{|l|}{ Sensitivity } & \multicolumn{3}{|l|}{ Severity } \\
\hline & $\operatorname{MITl}\left({ }^{\circ} \mathrm{C}\right)$ & MITc $\left({ }^{\circ} \mathrm{C}\right)$ & $\operatorname{LEL}\left(\mathrm{g} / \mathrm{cm}^{3}\right)$ & $\operatorname{MIE}(\mathrm{mJ})$ & $P_{\max }($ bar $)$ & $K_{\max }($ bar $\mathrm{m} / \mathrm{s})$ & LOC (\%) \\
\hline LRET-101 & 260 & 460 & 60 & 67 & 7.0 & 124 & 13 \\
\hline LRET-102 & 360 & 480 & 500 & $>1000$ & 5.0 & 77 & 20 \\
\hline LRET-103 & 300 & 480 & 60 & $>1000$ & 6.1 & 125 & 15 \\
\hline LRET-104 & 370 & 440 & 500 & $>1000$ & 5.5 & 108 & 13 \\
\hline LRET-105 & 370 & 420 & 125 & $>1000$ & 5.7 & 98 & 14 \\
\hline LRET-107 & 390 & 510 & 30 & $>1000$ & 6.3 & 178 & 14 \\
\hline LRET-110 & 390 & 510 & 125 & $>1000$ & 6.4 & 145 & 13 \\
\hline LRET-112 & 240 & 320 & 60 & 170 & 6.4 & 157 & 16 \\
\hline LRET-117 & 340 & 420 & 60 & 220 & 6.1 & 161 & 16 \\
\hline LRET-121 & 320 & 460 & 125 & $>1000$ & 6.1 & 161 & 19 \\
\hline
\end{tabular}

Table 5

Thermogravimetry.

\begin{tabular}{|c|c|c|c|c|c|c|}
\hline \multirow[b]{2}{*}{ Sample } & \multirow[b]{2}{*}{$\operatorname{TEV}\left({ }^{\circ} \mathrm{C}\right)$} & \multirow[b]{2}{*}{$\mathrm{Ml}\left(\mathrm{s}^{-1}\right)$} & \multicolumn{2}{|c|}{ Thermogravimetry } & \multicolumn{2}{|c|}{ Characteristics } \\
\hline & & & $\operatorname{MLT}\left({ }^{\circ} \mathrm{C}\right)$ & IT $\left({ }^{\circ} \mathrm{C}\right)$ & $T_{\text {charact }}\left({ }^{\circ} \mathrm{C}\right)$ & $E_{\mathrm{a}}(\mathrm{kJ} / \mathrm{mol})$ \\
\hline LRET-101 & 380 & 0 & 295.0 & 225 & 70.7 & 309 \\
\hline LRET-102 & 340 & 29 & 288.0 & 240 & 72.0 & 281 \\
\hline LRET-103 & 310 & 0 & 262.0 & 230 & 67.8 & 262 \\
\hline LRET-104 & 360 & 10 & 256.0 & 240 & 68.5 & 266 \\
\hline LRET-105 & 330 & 3 & 260.5 & 227 & 69.0 & 264 \\
\hline LRET-107 & 320 & 0 & 259.8 & 226 & 53.3 & 277 \\
\hline LRET-110 & 320 & 0 & 260.0 & 228 & 69.0 & 267 \\
\hline LRET-112 & 260 & 0 & 253.0 & 203 & 66.6 & 203 \\
\hline LRET-117 & 330 & 7 & 253.0 & 221 & 66.1 & 224 \\
\hline LRET-121 & 310 & 25 & 253.0 & 230 & 66.8 & 218 \\
\hline
\end{tabular}

Table 6

Differential scanning calorimetry.

\begin{tabular}{lcll}
\hline \multirow{2}{*}{ Sample } & \multicolumn{2}{c}{ Differential scanning calorimetry } \\
\cline { 2 - 4 } & IET $\left({ }^{\circ} \mathrm{C}\right)$ & FET $\left({ }^{\circ} \mathrm{C}\right)$ & CST $\left({ }^{\circ} \mathrm{C}\right)$ \\
\hline LRET-101 & 77 & 296 & 212 \\
LRET-102 & 114 & 345 & 194 \\
LRET-103 & 89 & 305 & 219 \\
LRET-104 & 118 & 317 & 193 \\
LRET-105 & 114 & 304 & 210 \\
LRET-107 & 120 & 303 & 206 \\
LRET-110 & 135 & 299 & 218 \\
LRET-112 & 117 & 288 & 182 \\
LRET-117 & 160 & 387 & 209 \\
LRET-121 & 153 & 319 & 209 \\
\hline
\end{tabular}

also have high variations, being of special interest that only three of the ten studied samples have a MIE under $1000 \mathrm{~mJ}$. Instead explosion severity parameters have a lower range of variation, and the $P_{\max }$ of the samples do not vary substantially among the studied samples. Finally, the values of the LOC show also a remarkable range of variation, from $13 \%$ to $20 \%$.

The parameters obtained from the thermogravimetry and the differential scanning calorimetry provide a range of variation narrower than chemical analyses, ignition sensitivity and explosion severity. The temperatures obtained from these tests do not vary in a range as wide as the ignition temperatures do, so the initial heating process of all the samples studied can be considered as quite similar. However, one of the most significant differences among the samples studied is the variation of the MI values. Only three samples produced a significant reaction, leading to a value higher or equal to 10 , and those samples are not the same as the samples with MIE lower than $1000 \mathrm{~mJ}$.

According to the data obtained for these ten samples, three of them were selected due to their diversity and thermal stability was studied for them. Two samples, LRET-102 and LRET-110, were analyzed according to the Division 4.2 tests and TSI was determined for the third sample, LRET-121. The results for LRET-102 and LRET-110 showed that they were exempted of hazardous classification when transported in packages of less than $3 \mathrm{~m}^{3}$. Test results for sample LRET-121 are shown in Table 7.

\section{Discussion}

\subsection{Relations among parameters}

To determine the relationships existing between chemical composition and explosibility parameters and also among the parameters within these two groups, a correlation analysis was done. The objective of this analysis was to determine the relations existing and define the parameters that could be easily modified by preventive measures and may cause a decrease on the explosion risk on this kind of industrial plants. With this analysis it is possible to see the similarity of the samples with other materials well-known as coal and biomass, and design prevention and protection systems based on those developed and widely experienced in other industrial plants.

To carry out these analyses, two groups of parameters have been analyzed. In the first group chemical and granulometry parameters were analyzed for 20 samples (twenty-sample group). In the second group, besides chemical composition and granulometry, also ignition sensitivity, explosion severity and thermal stability were studied for 10 samples (ten-sample group). From the data obtained from the analyses developed at laboratory, a correlation matrix has been determined in each case, and a Pearson's correlation analysis has been developed to each matrix, with a significant coefficient of 0.05 . Those correlations are studied in two groups, firstly the relationships existing among chemical parameters, and secondly between these parameters and flammability parameters or inside this last group. 
Table 7

Self-ignition temperature of sample LRET-121.

\begin{tabular}{|c|c|c|c|c|}
\hline Sample & Volume & Lower temperature leading to an ignition $\left({ }^{\circ} \mathrm{C}\right)$ & Higher temperature without ignition $\left({ }^{\circ} \mathrm{C}\right)$ & $\mathrm{TSI}\left({ }^{\circ} \mathrm{C}\right)$ \\
\hline \multirow[t]{4}{*}{ LRET-121 } & $1500 \mathrm{cc}$ & 125 & 120 & 122.5 \\
\hline & $350 \mathrm{cc}$ & 140 & 135 & 137.5 \\
\hline & $150 \mathrm{cc}$ & 145 & 140 & 142.5 \\
\hline & $50 \mathrm{cc}$ & 155 & 150 & 152.5 \\
\hline
\end{tabular}

\subsubsection{Chemical composition}

Looking only to the chemical parameters determined in this study, two main correlations groups have been observed.

The first group of parameters significantly correlated is formed by four composition parameters: carbon, hydrogen, volatiles and ashes content, as shown in Fig. 3. Added to the correlations, also histograms of each one of the parameters are represented, being the $Y$-axe the frequency of occurrence, the number of samples whose values are included inside the range represented in the $X$-axe. The correlations existing between carbon, hydrogen and volatiles are positive, unlike that observed between ash content and these three parameters. These correlations are due to the chemical composition of the sewage sludge. The first three parameters represent the organic content of the samples, while the ash content can be assimilated as the inorganic matter contained in the samples. As the organic matter of the samples is higher, the inorganic is lower.

The second group of significant correlations is observed between the three studied particle size parameters and it means that the tested samples have a high tendency to homogeneity as necessary in this tests. These correlations are illustrated on Fig. 4 besides the histograms of each parameter.

\subsubsection{Chemical composition and flammability}

Volatiles and ashes contents have a main influence on the flammability and explosibility of dusts. The main relations observed
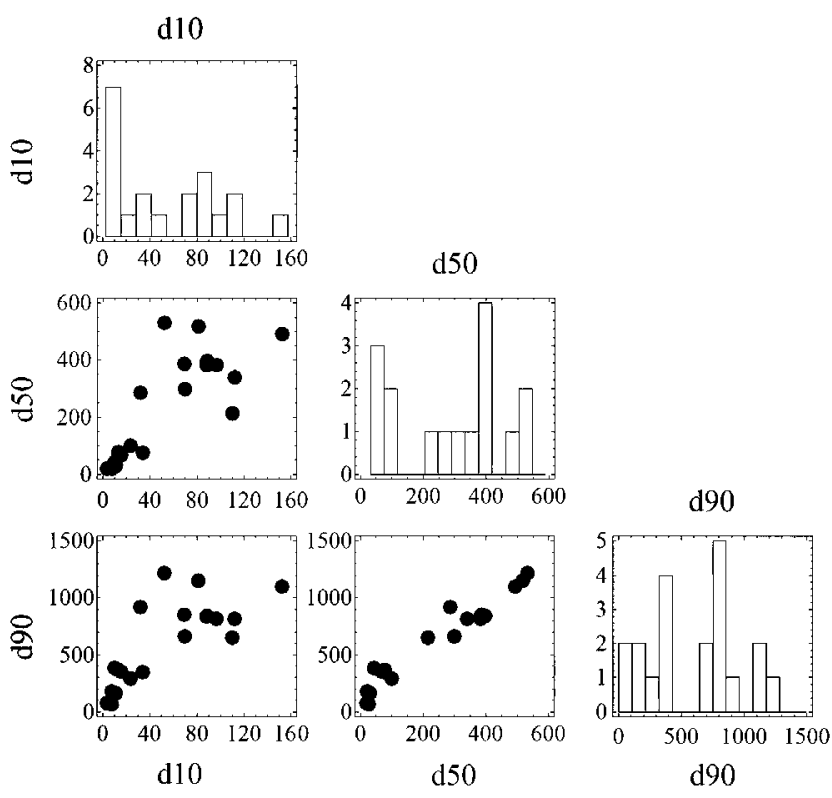

Fig. 4. Relations between $\mathrm{d} 10, \mathrm{~d} 50$ and $\mathrm{d} 90(\mu \mathrm{m})$.
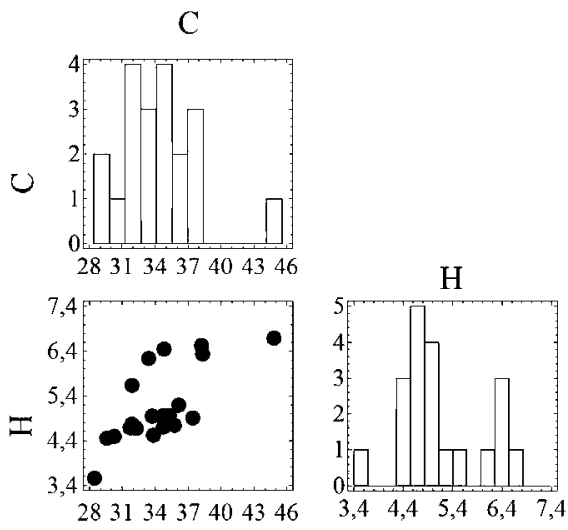

Ash
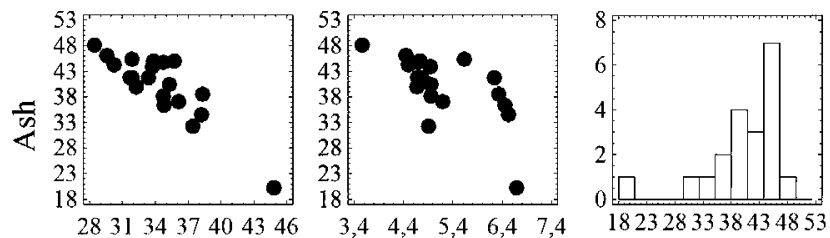

Volatiles
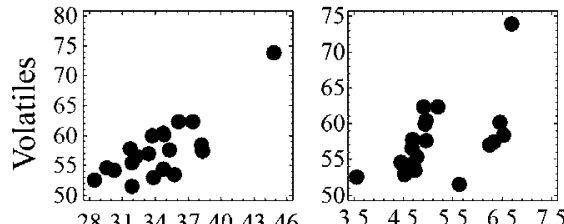

$\mathrm{C}$
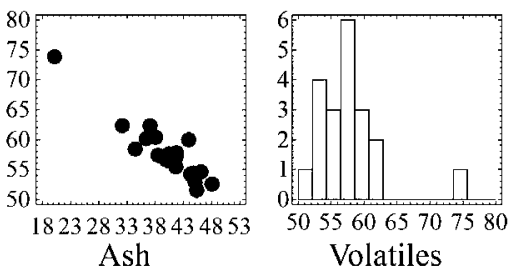

Fig. 3. Relations between $\mathrm{C}, \mathrm{H}$, ash and volatile content (\%). 
dealing these two parameters are those existing with MITl, MIE and $P_{\max }$, as shown in Fig. 5. As can be seen by the visible alignment formed by the data, the higher the volatiles content, the easier is the flammability of the samples (lower ignition temperatures and energies) and also higher explosibility (higher explosion pressures). However, ash content has a negative influence on the flammability so that higher ignition temperatures and higher ignition energies are required to ignite sludge samples containing a higher inorganic fraction and the obtained explosion pressure is lower.

The addition of inert dust to some combustible products is usually done to avoid the explosion, and this effect can be explained by these correlations among ashes content and the different parameters shown in Fig. 5. These correlations supply a method to decrease the ignition risk of the sewage sludge incorporating into the sample inert dust.

Hydrogen and sulfur showed a strong relation to the flammability parameters and this can be explained by the oxidation tendency of these components that are present in the sewage sludge.

Relationships were also observed between the decreasing particle size and an increase on the flammability of dusts and on the explosion severity. These relationships are observed in these samples between the medium diameter $(\mathrm{d} 50)$ and the MIE, MITl and IT as shown on Fig. 6.

The relationship existing between particle size and MITl has a double effect. In one hand, when the particle size is bigger, the gaps between the particles full of oxygen are larger, so the ignition easiness is higher. But in the other hand, the ignition is more difficult because the air is less conductive than the own substance. In this case, the second effect is stronger than the first one and by enlarging the particle size it is possible to increase the MITl and the ignition of a dust layer is more difficult. The same effect occurs with the IT, the higher the particle size, the higher the IT so the combustion of the sample starts at higher temperatures. Increasing the particle size and preventing the production of dust of extremely small particle size is also in this case a possibility to prevent the ignition risk in this kind of industrial plants.

Correlations with MIE do not lead to a line like in the other cases. Those are significant correlations because samples are grouped in two groups, one for these samples with less than $1000 \mathrm{~mJ}$ of MIE and another with more. Generally, the group with more than $1000 \mathrm{~mJ}$ has less volatile content, more ash content, more MITl and less $P_{\max }$. These relations are expected, but more samples are needed to ensure them.

In addition, looking at the relations existing among different flammability parameters, it is also observed a significant correlation among several temperatures studied. When a combustible substance is heated by a heat source, it begins to oxidize, and as the temperature increases it oxidizes more rapidly. At a certain point, the heat generated by the oxidation is sufficient to maintain the ignition without the aid of external sources. This point is the self-ignition temperature. Therefore, the three temperatures related to this ignition point (MITl, MITC and TEV) vary in the same direction as IT. Correlations related with MIE are similar as in the previous case, forming two groups of samples.
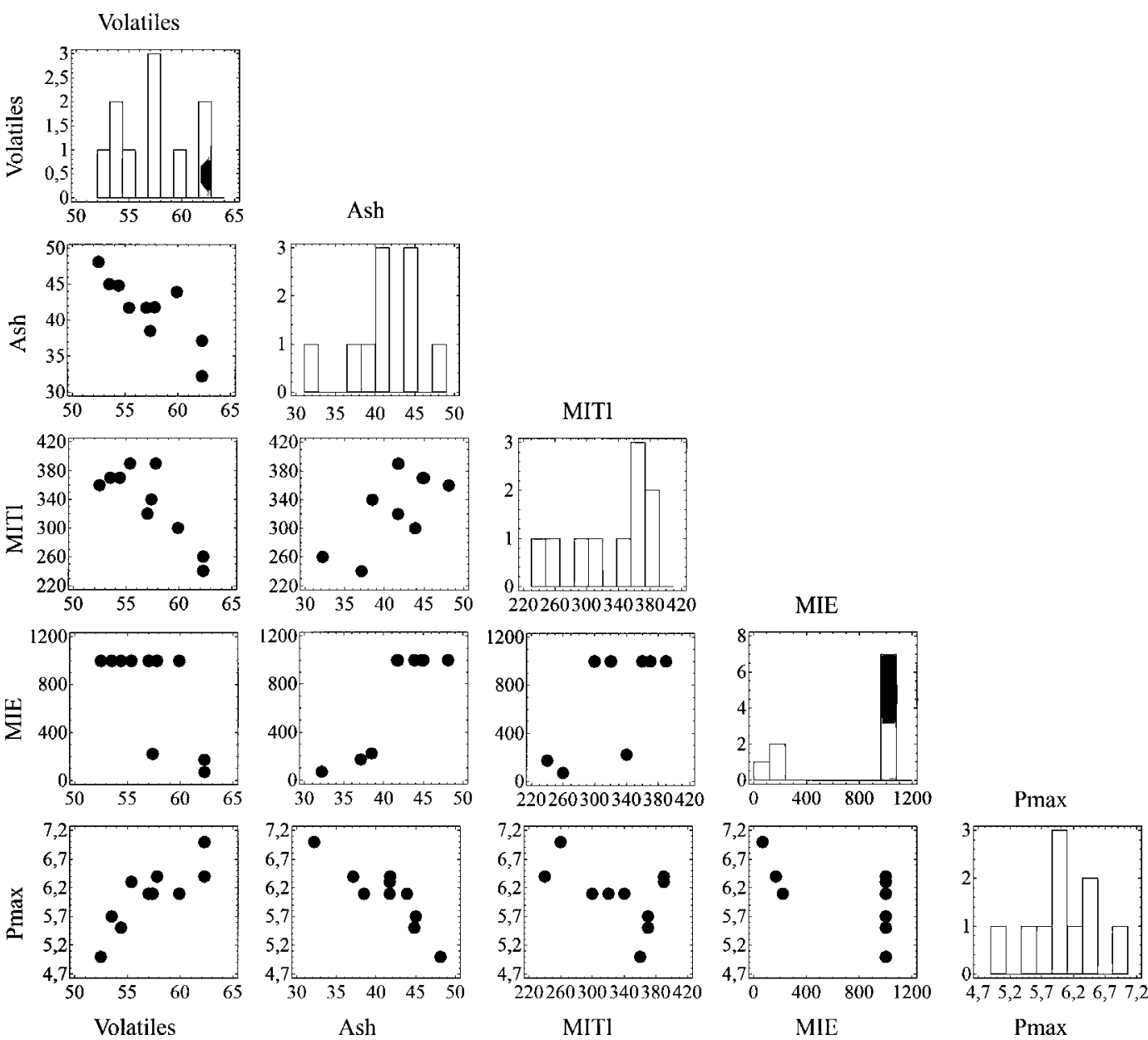

Fig. 5. Relations between volatile and ash content (\%) and MITl $\left({ }^{\circ} \mathrm{C}\right.$ ), MIE (mJ) and $P_{\max }$ (bar). 


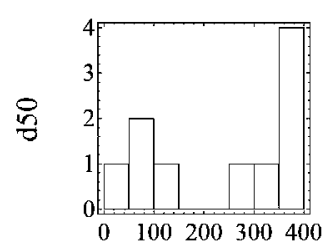

MIT1
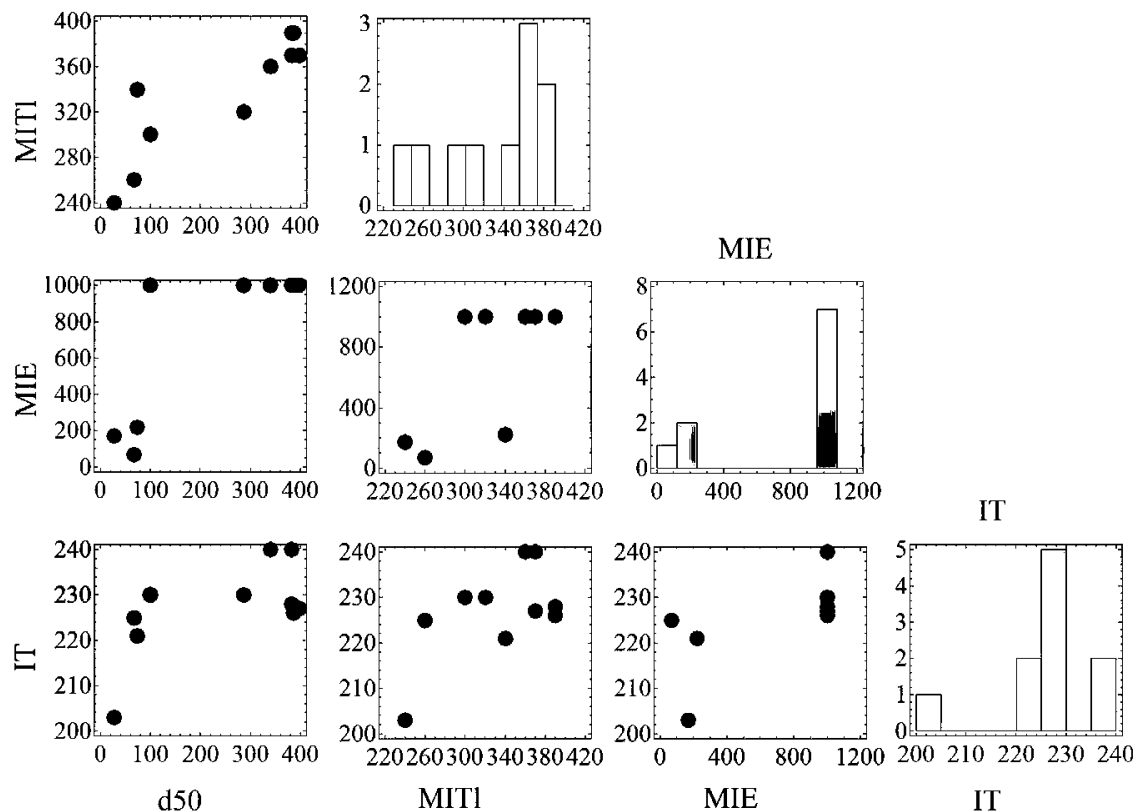

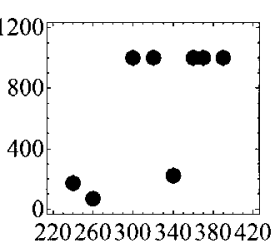

$\mathrm{d} 50$

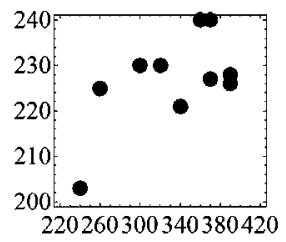

MIT1
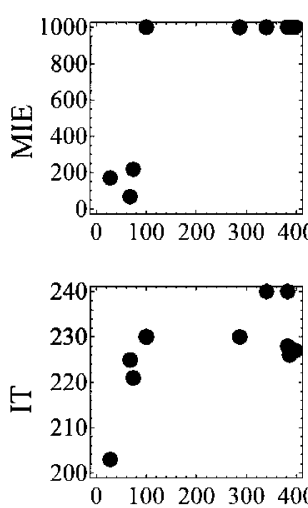

Fig. 6. Relations between medium diameter $(\mu \mathrm{m})$ and $\operatorname{MITI}\left({ }^{\circ} \mathrm{C}\right)$, MIE $(\mathrm{mJ})$ and $\mathrm{IT}\left({ }^{\circ} \mathrm{C}\right)$.
Other relations among temperatures are those more related with the volatiles content of the sample. It was found that the higher the volatiles content the more easily it ignites. Because of it, when the $T_{\text {charact }}$ increases, also other temperatures associated with those volatiles (MITc, TDM and TEV) increase, due to the $T_{\text {charact }}$ represents the temperature at which a quick combustion occurs. The exothermic reaction starts at lower temperatures as the reactivity of the substances increases (lower TDM) and the ignition of a dust cloud is easier (lower MITc). And in substances in which the quick exothermic reaction starts at low temperatures (lower TCP), the ignition of a cloud of sample is also easier.

Furthermore a relation was observed between ignition sensitivity and explosion severity, so that samples which need less dust concentration to ignite are those that produce the highest explosion pressures.

Finally, looking at the self-ignition risk of the sewage sludge, it was observed that when this risk is higher, the explosion severity is also higher.

\subsection{Influence of the origin and the season}

A discriminant analysis has been developed based on two different factors: the origin of the samples and the season when they were collected. This analysis was applied to the two groups of data previously described: chemical analysis (twenty-sample group) and flammability data (ten-sample group). In the second analysis, due to the linearity existing among the parameters of these ten samples, a principal component analysis (PCA) was developed.

In both groups, the discriminant analyses according to the origin of the sample showed that the $100 \%$ of the samples are correctly classified. In the first group, no significant discriminant function is observed. However, in the second group a significant discriminant function is determined, and the moisture of the sample is the main parameter that causes the classification, followed by its sulfur content.

The analysis according to the season shows that $95 \%$ of the samples included on the twenty-sample group and $90 \%$ on the tensample group are classified in the right group and only one of the samples is incorrectly classified in each case. In the first analysis realized to the twenty-sample data, one significant discriminant function has been determined. In this function, the parameters with more weight are the volatiles content and the carbon content. No significant discriminant function is observed in this case in the analysis done to the twenty-sample data.

\section{Conclusions}

The relations observed between the composition parameters depend on many factors, but they are not due to the drying process of the sewage sludge, otherwise they depend on the wastes treated and on the process followed in the wastewater treatment plant before the drying process.

The composition parameters that mainly affect to the explosibility of these dusts are chemical composition (volatiles and ashes) and particle size. These influences were expected since they were observed for many different materials in other studies, such as coal and biomass. These relations showed that in thermally drying sewage sludge plants it is possible to decrease the explosion risks or its effects applying similar actions as in coal and biomass treatment plants. For example, it is shown that the ashes content makes the sample less dangerous in terms of ignition, while the opposite occurs with the volatiles content, so it is possible to decrease the risk by increasing the inert part of the dust. 
Relations between the different measured temperatures showed the high dependency existing between different groups of parameters, and how the ignition, self-ignition and reactivity of the samples are related. It was also observed that the temperatures related with these actions vary together showing the same tendency. These relations show that by decreasing the risk of one of the parameters it is possible to decrease also others. For example, by increasing the particle size it is possible to heighten MIE, MITl and TIC because of the direct correlations observed, but also MITc, TEV, $T_{\text {charact }}$ and TDM will increase.

By the comparison of the discriminant analysis depending on the origin and on the sampling season, it is shown that the discrimination due to the origin is more accurate than the one due to the season. This shows that the sewage sludge ignition depends more of the origin of the sample than of the season. Even so, the percent age of correctly classified samples in order to the season is quite high, so the season is also an important parameter to classify the ignition tendency of sewage sludge. Also it is shown that the parameter that causes the differentiation of the samples according to their origin is the moisture of the samples, so this parameter varies greatly depending on the origin of the sample. And looking at the season when samples were collected, volatiles and carbon contents are the main reason for differentiating samples, which shows that the organic composition of the samples varies according to the season.

\section{Acknowledgment}

The authors gratefully acknowledge the Lloyd's Register Educational Trust for funding this study through the project Safety conditions against ATEX risk in the water industry.

\section{References}

[1] Daigger GT. Wastewater management in the 21st century. I Environ Eng ASCE 2007; 133:671-80.

[2] Daigger GT. Evolving urban water and residuals management paradigms: water reclamation and reuse, decentralization, and resource recovery. Water Environ Res 2009;81:809-23.

[3] Bixio D, Thoeye C, De Koning J, Joksimovic D, Savic D, Wintgens T, et al. Wastewater reuse in Europe. Desalination 2006;187:89-101.

[4] Spinosa L, Vesilind PA. Sludge into biosolids, processing disposal and utilization. London: IWA Publishing; 2001.

[5] Kelessidis A, Stasinakis AS. Comparative study of the methods used for treatment and final disposal of sewage sludge in European countries. Waste Manage (Oxford) 2012;32:1186-95.

[6] Brophy Mo. Hazards in Sewage (Waste) Treatment Plants. Encyclopedia of Occupational Health and Safety. Geneva: International Labour Organization; 2011. <http://www.ilo.org/oshenc/part-xvii/public-and-government-services/ item/831-hazards-in-sewage-waste-treatment-plants $>$.
[7] Joseph G. Combustible dusts: a serious industrial hazard. J Hazard Mater 2007;142:589-91.

[8] American Institute of Chemical Engineers. Is sugar an explosion hazard? J Fail Anal Preven 2008;8:311-2.

[9] Fodor Z, Klemeš IJ. Waste as alternative fuel-minimising emissions and effluents by advanced design. Process Saf Environ 2012;90:263-84.

[10] Eckhoff RK. Dust explosions in the process industries. Oxford: ButterworthHeinemann; 2003.

[11] Lebecki K. Functional safety in industrial explosion protection. Transactions 2012:44-8

[12] Amyotte PR, Eckhoff RK. Dust explosion causation, prevention and mitigation: an overview. J Chem Health Saf 2010;17:15-28.

[13] Ramírez Â, García-Torrent J, Aguado PJ. Determination of parameters used to prevent ignition of stored materials and to protect against explosions in food industries. J Hazard Mater 2009;168:115-20.

[14] Huéscar Medina $C$, Phylaktou $H$, Sattar $H$, Andrews G, Gibbs B. The development of an experimental method for the determination of the minimum explosible concentration of biomass powders. Biomass Bioenergy 2013:53:95-104.

[15] López-González D, Fernandez-Lopez $M$, Valverde J, Sanchez-Silva L. Thermogravimetric-mass spectrometric analysis on combustion of lignocellulosic biomass. Bioresour Technol 2013;143:562-74.

[16] Cashdollar KL. Coal dust explosibility. ] Loss Prevent Process 1996:9:65-76.

[17] Harrison EZ, Oakes SR, Hysell M, Hay A. Organic chemicals in sewage sludges. Sci Total Environ 2006;367:481-97.

[18] Metcalf L, Eddy HP, Tchobanoglous G. Wastewater engineering: treatment, disposal, and reuse. McGraw-Hill; 1972.

[19] Beamish B, Arisoy A. Effect of mineral matter on coal self-heating rate. Fue] 2008;87:125-30.

[20] Calle S, Klaba L, Thomas D, Perrin L, Dufaud O. Influence of the size distribution and concentration on wood dust explosion: experiments and reaction modelling. Powder Technol 2005;157:144-8.

[21] Eckhoff RK. Understanding dust explosions. The role of powder science and technology. J Loss Prevent Process 2009;22:105-16.

[22] Traorê M, Dufaud O, Perrin L, Chazelet S, Thomas D. Dust explosions: how should the influence of humidity be taken into account? Process Saf Environ 2009;87:14-20.

[23] Klippel A, Scheid M, Krause U. Investigations into the influence of dustiness on dust explosions. J Loss Prevent Process 2013;26:1616-26.

[24] Fuentes MJ, Font R, Gómez-Rico MF, Moltó J. Multivariant statistical analysis of PCDD/FS in sewage sludges from different areas of the Valencian Community (Spain). Chemosphere 2007;67:1423-33.

[25] García-Delgado M, Rodríguez-Cruz M, Lorenzo L, Arienzo M, Sánchez-Martín M. Seasonal and time variability of heavy metal content and of its chemical forms in sewage sludges from different wastewater treatment plants. Sci Total Environ 2007;382:82-92.

[26] Ramírez Á Garcia-Torrent J, Tascón A. Experimental determination of selfheating and self-ignition risks associated with the dusts of agricultural materials commonly stored in silos. J Hazard Mater 2010;175:920-7.

[27] García Torrent J, Cámara Rascón Â, Querol Aragón E. New thermogravimetric techniques applications for characterizing the susceptibility of coal to selfcombustion. In: XI Congreso Internacional de Industria, Minería y Metalurgia, Zaragoza; 2002.

[28] García Torrent J, Medic Pejic L, Querol Aragón E. A self-combustion chatacterisation index based in thermogravimetric and differential scanning calorimetry techniques, presented at the $V$ International Symposium on Hazards, Prevention and Mitigation of Industrial Explosions, Cracow (Poland); 2004. 